Published in final edited form as:

Curr Psychiatry Rep. 2012 October ; 14(5): 486-493. doi:10.1007/s11920-012-0296-5.

\title{
Personalized Treatment of Alcohol Dependence
}

\author{
Henry R. Kranzler and \\ Center for Studies of Addiction, Department of Psychiatry, Perelman School of Medicine of the \\ University of Pennsylvania, 3900 Chestnut Street, Philadelphia, PA 19104-6178, USA; \\ Philadelphia Veterans Affairs Medical Center, 3900 Woodland St., Philadelphia, PA 19104, USA \\ James R. McKay \\ Center for Studies of Addiction, Department of Psychiatry, Perelman School of Medicine of the \\ University of Pennsylvania, 3440 Market Street, Suite 370, Philadelphia, PA 19104, USA; \\ Philadelphia Veterans Affairs Medical Center, 3900 Woodland St., Philadelphia, PA 19104, USA, \\ jimrache@mail.upenn.edu
}

\section{Abstract}

Pharmacogenetic and adaptive treatment approaches can be used to personalize care for alcoholdependent patients. Preliminary evidence shows that variation in the gene encoding the $\mu$-opioid receptor moderates the response to naltrexone when used to treat alcohol dependence. Studies have also shown moderating effects of variation in the gene encoding the serotonin transporter on response to serotonergic treatment of alcohol dependence. Adaptive algorithms that modify alcohol treatment based on patients' progress have also shown promise. Initial response to outpatient treatment appears to be a particularly important in the selection of optimal continuing care interventions. In addition, stepped-care algorithms can reduce the cost and burden of treatment while maintaining good outcomes. Finally, matching treatment to specific problems present at intake or that emerge during treatment can also improve outcomes. Although all of these effects require replication and further refinement, the future of personalized care for alcohol dependence appears bright.

\section{Keywords}

Substance use; Alcohol dependence; Pharmacogenetics; OPRM1; Asn40Asp; A118G; Naltrexone; Nalmefene; Genetic moderation; 5-HTTLPR; Ondansetron; Sertraline; Adaptive trial designs; Adaptive protocol; Stepped care; Treatment algorithm

\section{Introduction}

Traditionally, diagnostic tests and medical treatments have been developed and evaluated using group data, a "one-size fits all" approach that leaves little room for individual variation [1]. Personalized medicine, which uses individual features to diagnose and treat disease, is of growing interest, having produced notable successes in oncology and cardiology [2•,3]. To date, there have been fewer advances in the personalized diagnosis and treatment of 
addictive disorders. However, ongoing developments in genetics and pharmacogenetics and in the use of adaptive trial designs offer great potential to extend these advances to the treatment of addiction, including alcohol dependence, the focus of this review [4-6].

Studies of adaptive trial designs have examined their utility in personalizing both pharmacological and behavioral therapies. In these studies, randomization is used at one or more points to determine the optimal treatment modifications for patients who are not responding adequately to the treatment they are receiving at that point [7]. The goal of adaptive trials is to develop algorithms for evidence-based treatment protocols to ensure the greatest likelihood of turning non-responders into responders. Thus, the growing use of adaptive study designs is highly relevant to personalized alcohol dependence treatment.

Adaptive treatment models, which specify when and how treatment should be modified for non-responders, can be generated by adaptive trials. However, adaptive treatments may also be developed by a consideration of research-based practice guidelines and the work of consensus panels [8•]. These models, which have also been referred to as "stepped care," "dynamic treatment regimes," "tailored interventions," and "treatment algorithms," are designed to improve outcomes by providing flexible care that is adjusted over time on the basis of patient response to treatment, according to clearly operationalized, empiricallyderived decision rules $[7,8 \bullet, 9]$.

Adaptive research trials and adaptive treatment protocols are relatively new. Most of the analytic and evaluative methods in this area come from prevention studies, cancer screening, and studies of hypertension, depression, and opioid addiction treatments [9-13].

\section{Pharmacogenetics of Alcohol Dependence Treatment}

Although there is a growing literature on genetic risk factors for alcohol dependence [14], we will focus on studies of genetic moderators of the pharmacotherapy of alcohol dependence. Here we extend a prior review [15] and focus on the genes encoding the $\mu$ opioid receptor and the serotonin transporter, the best studied genetic moderators of alcohol dependence treatment.

\section{The Opioidergic System}

Three types of opioid receptors $\mu, \kappa$, and $\delta$, bind opioid peptides to produce their biological effects [16]. The human genes encoding the $\mu$-opioid receptor (MOR; locus name OPRM1), the $\delta$ opioid receptor $(O P R D 1)$, and the $\kappa$-opioid receptor (OPRK1) are all expressed in the brain. Effects at the $\mu$-opioid receptor mediate the effects of many opioid agonists [17].

The most widely studied genetic moderator of alcohol treatment response is a variant identified in exon 1 of OPRM1 [18]. This common single nucleotide polymorphism (SNP), A118G, encodes an amino acid substitution (Asn40Asp) in the extracellular domain of the receptor. The frequency of the Asp40 (118G) allele varies widely by population, with the lowest frequency in African-Americans ( $<5 \%)$, an intermediate frequency in those of European ancestry $(2.5 \% 201315.5 \%)$, and the highest frequency in Asians ( $25 \%-47 \%$ ) 
[19]. The effect of the variant allele on MOR function in human brain is controversial, with evidence for both loss of function and gain of function [15].

\section{Human Laboratory Studies}

Following intravenous alcohol administration, Asp40-allele carriers reported experiencing a more intense "high" and greater subjective intoxication, stimulation, sedation, and happiness than Asn40 homozygotes [20]. In an alcohol cue-exposure study, male heavy drinkers with an Asp40 allele reported higher levels of craving than did Asn40 homozygotes [21].

Human laboratory studies have also been used to examine naltrexone's effects on the subjective response to alcohol or alcohol-related cues. A within-subject, double-blind study examined the effects of pre-treatment with naltrexone or placebo on the response to intravenous alcohol in a sample of non-treatment-seeking heavy drinkers [22]. Although Asp40-allele carriers experienced lower levels of alcohol craving and greater alcoholinduced "high" as the breath alcohol concentration was increased, naltrexone blunted the positive response to alcohol, most robustly in individuals Asp40 carriers. In contrast, McGeary et al. [23] found that naltrexone pretreatment paradoxically was associated with greater cue-elicited craving than placebo in heavy drinkers with an Asp40 allele. No such difference was seen in Asn40-allele homozygotes.

\section{Clinical Trials of Opioid Receptor Antagonists to Treat Alcohol Dependence}

Although meta-analyses of alcohol dependence treatment [24, 25] show that naltrexone is superior to placebo on a number of drinking outcomes, there is considerable variability in efficacy among studies, suggesting that the medication is not efficacious for all patients. The finding that individuals with a greater percentage of alcoholic family members show a more robust treatment response [26-28] has led to an effort to identify genetic variants that can be used as biomarkers in alcohol-dependent individuals to identify who is most likely to benefit from opioid antagonist treatment.

The first report of differential naltrexone response to carriers of the Asp40 allele was by Oslin et al. [5], in a secondary analysis of data from 130 European-American (EA) participants in 3 placebo-controlled trials of naltrexone. In that study, patients with 1 or 2 Asp40 alleles were significantly less likely than Asn40 homozygotes to relapse to heavy drinking when treated with naltrexone. Although a formal interaction was not detected, there was no effect of the SNP in placebo-treated subjects. Gelernter, et al. [29] examined the moderating effect of 3 OPRM1 SNPs (including Asn40Asp), 3 polymorphisms in OPRD1, and 1 poly- morphism in $O P R K 1$ on treatment outcome in 215 patients from the VA Cooperative Study of Naltrexone Treatment [30]. They found no evidence of genetic moderation of the response to naltrexone treatment. Anton, et al. examined the Asn40Asp SNP in 911 participants in the COMBINE Study [31]. Using genotype information for EAs who were randomly assigned to naltrexone or placebo, they found a moderating effect of the Asp40 allele in the subjects who received naltrexone and medical management, but not in those that received naltrexone and a more intensive psychotherapy.

Open-label studies of naltrexone in alcohol-dependent individuals have also yielded equivocal findings. In a study of naltrexone treatment of Korean alcoholics [32], analysis of 
the moderating effect of the Asn40Asp SNP was limited to participants who were treatment adherent. Carriers of the Asp40 allele showed a longer time to relapse than Asn40homozygotes. An Australian study of naltrexone in 100 alcohol-dependent individuals [33] was associated with decreases in self-reported and objective indicators of alcohol use and craving from pretreatment levels. However, there was no evidence of a significant effect of the Asn40Asp SNP on a variety of drinking outcomes.

Kranzler et al. [34] examined the moderating effect of the Asn40Asp SNP on medication response in a placebo-controlled trial of daily or targeted naltrexone in problem drinkers who sought to reduce their drinking. In the aggregate, the SNP did not significantly moderate the effect of naltrexone on drinking behavior. However, by using a daily diary method in which patients reported by telephone each evening their current desire to drink and their drinking during the preceding day they were able successfully to show that genotype, medication, desire to drink and their interactions predicted the number of nighttime drinks consumed. Interesting, when the evening level of desire to drink was relatively high, Asp40 allele carriers were at greater risk than Asn40 homozygotes to drink more, which was attenuated by naltrexone. This is consistent with a modest effect of the Asn40Asp SNP and appeared to depend on the greater statistical power resulting from the "micro-longitudinal" study design.

There is also one study [35] of the moderating effects of genetic variation on treatment response in a sub-sample of alcohol-dependent patients from a placebo-controlled trial of nalmefene [36], an opioid antagonist with partial agonist effects at the $\kappa$ receptor [37]. Although nalmefene significantly reduced the weekly number of heavy drinking and very heavy drinking days, there was no evidence of moderation by 2 SNPs in OPRM1 (including Asn40Asp), 2 SNPs in OPRD1, or $1 \mathrm{SNP}$ in OPRK1.

\section{Trials of Naltrexone in Non-Treatment-Seeking Heavy Drinkers}

In a placebo-controlled, cross-over trial of naltrexone in 30 non-treatment-seeking individuals, 1 week of naltrexone treatment reduced drinking behavior more than 1 week of placebo treatment [38]. However, there was no moderating effect of the Asp40 allele on the response to naltrexone. Tidey et al. [39] found no moderating effect of the Asp40 allele on drinking outcomes in a 3-week, placebo-controlled trial of naltrexone in 173 heavy drinkers.

\section{Summary}

The moderating effect of the OPRM1 Asn40Asp SNP on the efficacy of naltrexone in reducing heavy drinking is, overall, modest. The considerable differences among studies may reflect variation in study populations and methods. In addition to small sample sizes in some studies, the imbalance in the frequency of the alleles being studied limits the statistical power of these retrospective comparisons. Although a preliminary meta-analysis showed evidence of significant moderation of the effects of naltrexone on risk of heavy drinking by the Asn40Asp polymorphism [40], large, prospective studies are needed to estimate more accurately the magnitude of the moderating effect of the Asn40Asp SNP on the efficacy of naltrexone. Although the only published pharmacogenetic study of nalmefene failed to show evidence of a moderating effect of the Asn40Asp SNP, because this medication is being 
developed for use in the European Union, additional studies of nalmefene appear warranted. Variants in other opioid-related genes (both receptors and peptide ligands) should also be considered as potential moderators of treatment with naltrexone and nalmefene.

\section{The Serotonergic System}

Medications that modify serotonin (5-HT) neurotransmission, including selective serotonin reuptake inhibitors (SSRIs) and specific 5-HT receptor blockers have been studied as potential treatments for alcohol dependence. Although in rodents, manipulations that increase 5-HT consistently reduce drinking [41], 5-HT agonists have yielded inconsistent effects on drinking in humans [42]. This suggests that phenotypic or genotypic subtypes of alcohol dependence could affect the response to serotonergic medications [42].

Studies of phenotypic variation in this response have focused on age of onset and risk/ vulnerability subtypes [43-46]. Two studies showed that early-onset or high vulnerability participants treated with fluoxetine or fluvoxamine had poorer outcomes than those receiving placebo [43, 44], whereas 1 study [45] showed a significant advantage of sertraline in late-onset low-risk/vulnerability patients. Ondansetron, a 5- $\mathrm{HT}_{3}$ antagonist, was shown in a placebo-controlled trial [46] to reduce drinking among early-onset alcoholics. In this study early-onset alcoholics treated with low-dose ondansetron (ie, 1, 4, or $16 \mathrm{mg} / \mathrm{kg} / \mathrm{day}$ ) had significantly more abstinent days and significantly less alcohol consumption than the placebo group. In alcoholics with a later onset of problem drinking, the effects of ondansetron did not differ from those of placebo.

Studies of the pharmacogenetics of serotonergic medications have focused on $S L C 6 A 4$, the gene encoding the 5-HT transporter (5-HTT), which regulates 5-HT tone. A 44-bp repeat insertion in the 5-HTT linked promoter region (5-HTTLPR) of SLC6A4 results in long (L) and short (S) alleles [47]. Due to different transcriptional activity these alleles encode higher-activity and lower-activity 5-HTT proteins, respectively [48]. An A-to-G SNP (rs25531) in the L-specific repeat of the gene also affects function, such that the $\mathrm{L}_{\mathrm{G}}$ allele is functionally similar to the lower-activity $\mathrm{S}$ allele $[49,50]$. Two placebo-controlled trials have shown moderating effects of variation in $S L C 6 A 4$ on the response to serotonergic medications.

Johnson et al. [51•] randomly assigned alcohol-dependent patients to receive 11 weeks of double-blind treatment with ondansetron or placebo. Individuals with the 5-HTTLPR LL genotype who were treated with ondansetron drank significantly fewer drinks per drinking day and had a significantly higher percentage of abstinent days than those who received placebo. Further, ondansetron patients with the LL genotype reported significantly better outcomes on both of these measures than individuals with an $\mathrm{S}$ allele. There was also an interaction between the 5'-HTTLPR and 3'-UTR polymorphisms: ondansetron-treated patients with both the LL 5-HTTLPR genotype and the TT 3' UTR genotype drank significantly fewer drinks per drinking day and had a higher percentage of days abstinent than all other genotype and treatment groups combined.

Kranzler et al. [52], in a 12-week, placebo-controlled trial of sertraline, examined the moderating effects of both age of onset of alcohol dependence and 5-HTTLPR genotype on 
drinking behavior in alcohol-dependent subjects. Whereas, in late-onset alcoholics, sertraline treatment reduced drinking behavior more than placebo, in early-onset alcoholics, greater reductions were seen with placebo treatment. This interaction effect occurred only in highactivity-allele (ie, L'-allele) homozygotes. Follow-up of these patients showed that the effect of sertraline remained significant during the 3-month post-treatment period for L'/L' lateonset alcoholics, with the sertraline group having significantly fewer drinking days than the placebo group, with no other significant effects of at 3-month or 6-month follow-up visits.

The findings that the effects of ondansetron and sertraline, which are different neuropharmacologically, are both moderated by high-activity alleles of 5-HTTLPR may reflect a shared underlying mechanism for these medications. That is, the synaptic availability of 5-HT, which is influenced by both SSRI treatment and 5-HTTLPR, can determine the extent to which the predominantly post-synaptic $5-\mathrm{HT}_{3}$ receptors, which are the primary target of ondansetron, are stimulated. Efforts to replicate these findings is needed, as is further examination of variation in SLC6A4 that may affect expression of the 5-HTT and augment the moderating effects observed to date.

\section{Adaptive Treatment Approaches}

Patient progress while in treatment can also be used to personalize interventions for alcohol use disorders. Approaches to the treatment of medical and behavioral disorders in which changes in symptoms or status are monitored over time and used to adjust the treatment protocol according to well-specified guidelines are referred to as "adaptive" treatment protocols $[7,8 \bullet$. Adaptive treatments can also incorporate tailoring on the basis of patient characteristics assessed at intake—such as genetics—-to further personalize care.

The main components of an adaptive treatment are tailoring variables, therapeutic components, and decision rules [7]. Tailoring variables are the measures that are used to monitor patient progress. In the case of alcohol dependence, alcohol use will often be used as a tailoring variable. How-ever, measures such as attendance in treatment sessions or selfhelp groups, self-efficacy, coping behavior, or motivation could also be used as tailoring variables [8•]. For example, decisions to increase or decrease the intensity of treatment over time might be driven by changes in the patient's perceived ability to cope with various problems without drinking (ie abstinence self-efficacy).

In an adaptive protocol, treatment can be modified by augmenting the current intervention or switching to another intervention altogether. The key concern here is for the other intervention to have a sufficiently different mechanism of action that it has a reasonable chance of success where the initial intervention failed. Decision rules are the "if-then" statements that link responses on the tailoring variables to specific changes in therapeutic components or procedures. An example of a decision rule might be: "If the patient has 3 or more heavy drinking days within a 7-day period, augment standard outpatient treatment with individual CBT sessions." Decision rules are clearly operationalized, and they involve specified cutting scores on the tailoring variables and specified treatment selections. 


\section{Adaptive Alcohol Treatment Studies}

Bischof and colleagues [53] described an adaptive, telephone-based, stepped-care approach for problem drinkers in medical practices in Germany. Individuals with alcohol use disorders were randomly assigned to 1 of 3 conditions: usual care, full care, or stepped care. Both the full care and stepped care models included a computerized intervention plus 4 subsequent telephone-based intervention sessions. In the stepped care version, the number of telephone contacts was determined by response to the intervention. In the full care version, all 4 telephone contacts were delivered. Both active interventions produced better drinking outcomes at 12 months than standard care. Drinking outcomes in the stepped care and full care conditions did not differ, even though participants in the stepped care condition received about half as many treatment sessions. Thus, the stepped care algorithm reduced patient burden and cost to the system, with no compromise on effectiveness [8•].

McKay and colleagues have conducted a series of studies to determine whether initial progress in outpatient treatment can predict optimal continuing care interventions. The first study found that alcohol-dependent patients who did not achieve abstinence during a 4-week intensive outpatient program (IOP) had much worse drinking outcomes over a 24-month follow-up than those who stopped drinking. How-ever, individuals who failed to achieve abstinence benefited more from a CBT-based continuing care intervention than from standard group continuing care. In contrast, there were no treatment differences in patients who had stopped drinking while in IOP [54]. In a second study, IOP patients who did not achieve the majority of the goals of IOP during the first month of treatment had better substance use outcomes if they subsequently received more intensive, clinic-based continuing care, whereas for those who made better progress in IOP, telephone continuing care was superior to clinic treatment [55]. Of the goals examined, alcohol use in IOP was the strongest single predictor of optimal continuing care selection [56]. Finally, a recent study found that augmenting IOP with extended continuing care was particularly beneficial in comparison to IOP only for patients who had low motivation for change and poor social support for recovery at the one-month point in IOP. Women and patients with prior treatments for alcoholism also benefited to a greater degree from extended continuing care [57].

O'Malley and colleagues [58] conducted a study to determine optimal continuation treatments for alcohol-dependent patients who initially responded positively to naltrexone. Patients were randomized to receive naltrexone in a primary medical care setting or in an addiction specialty care setting that provided cognitive-behavioral therapy (CBT) for alcohol dependence. Patients who achieved a good response over the first 10 weeks were randomized for a second time to either extended naltrexone or placebo, along with continuation of the behavioral treatment they had received in Phase 1. The continuation treatments were provided for an additional 24 weeks [8•].

The the primary care and CBT conditions were equivalent on most drinking outcomes during the first 10 weeks of the study. However, in the continuation phase, patients receiving primary care-based treatment had better drinking outcomes if they received extended naltrexone (ie, $81 \%$ of those in the naltrexone condition were responders, compared with only $52 \%$ in the placebo condition). Conversely, those who received CBT did not benefit 
from extended naltrexone [58]. This study illustrates how the effectiveness of later treatment interventions can vary as a function of which intervention patients received earlier in the protocol [8].

Friedmann and colleagues [59] conducted a large-scale study of services-to-needs matching, with a sample of over 3100 addiction treatment patients. The study focused on the degree to which reported needs in 5 domains - medical, mental health, family, vocational, and housing -were addressed with services, and whether better matching produced better substance use outcomes. Overall, higher rates of services-to-problems matching predicted better substance use outcomes. The effect was concentrated in patients who reported problems in at least 4 of the 5 domains, and matching of vocational and housing services was particularly important [59].

\section{Adaptive Treatment Studies with Drug Dependent Patients}

We describe here a number of adaptive trials conducted to treat drug dependence because of the limited number of such studies with alcohol-dependent individuals and the potential that findings from drug dependence studies can also improve alcohol treatment. Brooner and Kidorf [60] developed a stepped care treatment for methadone patients, in which movement between 3 levels of counseling intensity was determined by attendance and urine toxicology results. Failure to attend treatment sessions or drug-positive urines triggered increases in the intensity of counseling provided to patients. Studies by this group indicate that this stepped care approach works equally well in methadone clinics or at physicians' offices [61], can be adapted to increase employment rates in methadone patients [62], and can be combined with contingency management to further improve outcomes [63]. A stepped care algorithm for opiate dependent patients that first provides buprenorphine and steps non-responders up to methadone maintenance was shown to be as effective as starting patients on methadone [64]. Therefore, the stepped care algorithm reduced patient burden and increased safety, without sacrificing good substance use outcomes.

Finally, Marlowe and colleagues [65] conducted a study of an adaptive intervention for drug court participants. In this study, offenders were initially assigned to bi-weekly or "as needed" hearing schedules on the basis of whether they carried a diagnosis of Antisocial Personality Disorder or had a history of prior treatments for substance dependence. This initial hearing schedule could be further adapted on the basis of outcomes in drug court. Offenders who attended drug court but were using drugs were given intensive case management to provide them with additional skills needed to achieve abstinence. Conversely, for those who failed to attend scheduled drug court sessions, their hearings were increased in frequency to bi-weekly, or they were terminated from the program and sentenced on their original drug charges if they had been placed on the bi-weekly schedule at the start of the study. This adaptive algorithm produced better drug use outcomes than standard drug court. This study is a good example of how tailoring on the basis of patient characteristics at intake can be combined with an adaptive algorithm driven by progress during treatment [8•]. Furthermore, it illustrates that it is possible to adapt treatment using two tailoring variables (ie attendance and drug use), with different modifications for each 
variable (ie increased frequency of sessions and augmentation with clinical care management).

\section{Conclusion}

Developments in the pharmacotherapy of alcoholism and in the genetics of alcohol dependence have informed studies that match medications to patients based on genotype. The literature in this area is, however, only beginning to develop and the vast majority of studies have used comparatively small samples of convenience, rather than employing prospective designs in adequately powered samples. Despite conflicting results of studies of the Asn40Asp SNP in OPRM1 as a moderator of the effects of naltrexone, this remains the most clinically relevant observation to date. Prospective studies may help to resolve controversy in relation to this effect.

Both of the placebo-controlled trials of alcohol dependence treatment that examined the moderating effects of the 5-HTTLPR polymorphism on the response to serotonergic medications showed that L-allele homozygotes responded differentially to the active treatments, despite their different pharmacological mechanism of action. Additional prospective studies of ondansetron and other serotonergic agents are needed to validate the use of this polymorphism as a predictor of treatment response. An-other important question to be addressed is whether the tri-allelic polymorphism $\left(\mathrm{L}_{\mathrm{A}} \mathrm{vs}_{\mathrm{G}}\right.$ or $\left.\mathrm{S}\right)$ is a more robust moderator of treatment response in alcohol dependence than the bi-allelic polymorphism $(\mathrm{L}$ vs $S)$.

To be highly successful financially,, medications are marketed to large portions of the population, irrespective of individual features. The identification of patient characteristics that would allow a medication to be targeted to individuals for whom it would be most efficacious and least toxic would limit the size of the market for that medication. A shift from this wholesale approach to medications development to one that personalizes medication choices could improve the treatment of alcohol dependence.

Recent research also indicates that treatments for alcohol and drug dependence can be personalized through the incorporation of adaptive algorithms that are designed to modify treatment on the basis of patient progress. Initial response to outpatient treatment-as indicated by whether the patient is able to stop using alcohol and other drugs- appears to be a particularly good predictor of the type of continuing care that will achieve the best substance use outcomes [54, 56, 65]. In addition, stepped-care algorithms that start at a lower intensity are able to reduce the cost and burden of treatment while maintaining good outcomes [53, 63, 64]. Finally, matching treatment to specific problems present at intake, or that emerge during treatment, such as poor social support and low motivation, homelessness, and employment problems, can also improve treatment [57, 59].

\section{Acknowledgments}

Related work by the authors is supported by grants K24 AA13736 (to HRK) and K24 DA029062 and P01 AA016821 (to JRM) from the National Institutes of Health. 
Disclosure H. R. Kranzler: consulting fees from Alkermes, Gilead, GlaxoSmithKline, Lilly, Lundbeck, Pfizer, Roche, Sanofi-Aventis, and Solvay; research support from Merck; and honoraria from the American College of Neuropsychopharmacology's Alcohol Clinical Trials Initiative (ACTIVE), which was supported by Lilly, Janssen, Schering Plough, Lundbeck, Alkermes, GlaxoSmithKline, Abbott, and Johnson \& Johnson; J. R. McKay: consulting fees from Human Service Center.

\section{References}

Papers of particular interest, published recently, have been highlighted as:

- Of importance

1. Evers K Personalized medicine in psychiatry: ethical challenges and opportunities. Dialogues Clin Neurosci 2009;11(4):427-34. [PubMed: 20135900]

2•. Hamburg MA, Collins FS The path to personalized medicine. N Engl J Med 2010;363(4):301-4. [PubMed: 20551152] Provides an overview of progress in personalized medicine and a vision for its subsequent development. Written by the leaders of the United States Food and Drug Administration and the National Institutes of Health.

3. Damani SB, Topol EJ. The case for routine genotyping in dual-antiplatelet therapy. J Am Coll Cardiol 2010;56(2):109-11. [PubMed: 20471193]

4. Berrettini W, Yuan X, Tozzi F, Song K, Francks C, Chilcoat H, et al. Alpha-5/alpha-3 nicotinic receptor subunit alleles increase risk for heavy smoking. Mol Psychiatry 2008;13(4):368-73. [PubMed: 18227835]

5. Oslin DW, Berrettini W, Kranzler HR, Pettinati H, Gelernter J, Volpicelli JR, et al. A functional polymorphism of the mu-opioid receptor gene is associated with naltrexone response in alcohol-dependent patients. Neuropsychopharmacology 2003;28(8):1546-52. [PubMed: 12813472]

6. Ray R, Tyndale RF, Lerman C. Nicotine dependence pharmacogenetics: role of genetic variation in nicotine-metabolizing enzymes. J Neurogenet 2009;23(3):252-61. [PubMed: 19169923]

7. Murphy SA, Oslin DW, Rush AJ, Zhu J. Methodological challenges in constructing effective treatment sequences for chronic psychiatric disorders. Neuropsychopharmacology 2007;32 (2):25762. [PubMed: 17091129]

8•. McKay J Treating Substance Use Disorders with Adaptive Continuing Care Washington: American Psychological Association Press; 2009.The first book to be published that describes how adaptive treatment interventions are designed and evaluated, and presents a detailed description and review of adaptive treatment studies that have been done in the addictions.

9. Collins LM, Murphy SA, Bierman KL. A conceptual framework for adaptive preventive interventions. Prev Sci 2004;5(3):185-96. [PubMed: 15470938]

10. ALLHAT Collaborative Research Group. Major outcomes in high-risk hypertensive patients randomized to angiotensin-converting enzyme inhibitor or calcium channel blocker vs diuretic: The Antihypertensive and Lipid-Lowering Treatment to Prevent Heart Attack Trial. JAMA 2002;288(23):2981-97. [PubMed: 12479763]

11. Rakowski W, Lipkus IM, Clark MA, Rimer BK, Ehrich B, Lyna PR, et al. Reminder letter, tailored stepped-care, and self-choice comparison for repeat mammography. Am J Prev Med 2003;25 (4): 308-14. [PubMed: 14580632]

12. Rush AJ, Trivedi MH, Wisniewski SR, Stewart JW, Nierenberg AA, Thase ME, et al. BupropionSR, sertraline, or venlafaxine-XR after failure of SSRIs for depression. N Engl J Med 2006;354(12):1231-42. [PubMed: 16554525]

13. Trivedi MH, Fava M, Wisniewski SR, Thase ME, Quitkin F, Warden D, et al. Medication augmentation after the failure of SSRIs for depression. N Engl J Med 2006;354(12):1243-52. [PubMed: 16554526]

14. Gelernter J, Kranzler HR. Genetics of alcohol dependence. Hum Genet 2009;126(1):91-9. [PubMed: 19533172]

15. Edenberg HJ, Kranzler HR. The contribution of genetics to addiction therapy approaches. Pharmacol Ther 2005;108(1):86-93. [PubMed: 16026844] 
16. Kieffer BL. Recent advances in molecular recognition and signal transduction of active peptides: receptors for opioid peptides. Cell Mol Neurobiol 1995;15(6):615-35. [PubMed: 8719033]

17. Yu L The mu opioid receptor: from molecular cloning to functional studies. Addict Biol 1996;1(1): 19-30. [PubMed: 12893484]

18. Bergen AW, Kokoszka J, Peterson R, Long JC, Virkkunen M, Linnoila M, et al. Mu opioid receptor gene variants: lack of association with alcohol dependence. Mol Psychiatry 1997;2 (6):490-4. [PubMed: 9399694]

19. Arias A, Feinn R, Kranzler HR. Association of an Asn40Asp (A118G) polymorphism in the muopioid receptor gene with substance dependence: a meta-analysis. Drug Alcohol Depend 2006;83(3):262-8. [PubMed: 16387451]

20. Ray LA, Hutchison KE. A polymorphism of the mu-opioid receptor gene (OPRM1) and sensitivity to the effects of alcohol in humans. Alcohol Clin Exp Res 2004;28(12):1789-95. [PubMed: 15608594]

21. van den Wildenberg E, Wiers RW, Dessers J, Janssen RG, Lambrichs EH, Smeets JH, et al. A functional polymorphism of the mu-opioid receptor gene (OPRM1) influences cue-induced craving for alcohol in male heavy drinkers. Alcohol Clin Exp Res 2007;31(1):1-10. [PubMed: 17207095]

22. Ray LA, Hutchison KE. Effects of naltrexone on alcohol sensitivity and genetic moderators of medication response: a double-blind placebo-controlled study. Arch Gen Psychiatry 2007;64(9): 1069-77. [PubMed: 17768272]

23. McGeary JE, Monti PM, Rohsenow DJ, Tidey J, Swift R, Miranda R, Jr. Genetic moderators of naltrexone's effects on alcohol cue reactivity. Alcohol Clin Exp Res 2006;30(8):1288-96. [PubMed: 16899031]

24. Bouza C, Angeles M, Munoz A, Amate JM. Efficacy and safety of naltrexone and acamprosate in the treatment of alcohol dependence: a systematic review. Addiction 2004;99(7):811-28. [PubMed: 15200577]

25. Srisurapanont M, Jarusuraisin N. Naltrexone for the treatment of alcoholism: a meta-analysis of randomized controlled trials. Int J Neuropsychopharmacol 2005;8(2):267-80. [PubMed: 15850502]

26. Monterosso JR, Flannery BA, Pettinati HM, Oslin DW, Rukstalis M, O’Brien CP, et al. Predicting treatment response to naltrexone: the influence of craving and family history. Am J Addict 2001;10 (3):258-68. [PubMed: 11579624]

27. Rubio G, Ponce G, Rodriguez-Jimenez R, Jimenez-Arriero MA, Hoenicka J, Palomo T. Clinical predictors of response to naltrexone in alcoholic patients: who benefits most from treatment with naltrexone? Alcohol Alcohol 2005;40(3):227-33. [PubMed: 15797885]

28. Krishnan-Sarin S, Krystal JH, Shi J, Pittman B, O’Malley SS. Family history of alcoholism influences naltrexone-induced reduction in alcohol drinking. Biol Psychiatry 2007;62(6):694-7. [PubMed: 17336941]

29. Gelernter J, Gueorguieva R, Kranzler HR, Zhang H, Cramer J, Rosenheck R, et al. Opioid receptor gene (OPRM1, OPRK1, and OPRD1) variants and response to naltrexone treatment for alcohol dependence: results from the VA Cooperative Study. Alcohol Clin Exp Res 2007;31(4):555-63. [PubMed: 17374034]

30. Krystal JH, Cramer JA, Krol WF, Kirk GF, Rosenheck RA. Naltrexone in the treatment of alcohol dependence. N Engl J Med 2001;345(24):1734-9. [PubMed: 11742047]

31. Anton RF, O’Malley SS, Ciraulo DA, Cisler RA, Couper D, Donovan DW, et al. Combined pharmacotherapies and behavioral interventions for alcohol dependence: the COMBINE study: a randomized controlled trial. JAMA 2006;295(17):2003-17. [PubMed: 16670409]

32. Kim SG, Kim CM, Choi SW, Jae YM, Lee HG, Son BK, et al. A micro opioid receptor gene polymorphism (A118G) and naltrexone treatment response in adherent Korean alcohol-dependent patients. Psychopharmacology (Berl) 2009;201(4):611-8. [PubMed: 18795264]

33. Coller JK, Cahill S, Edmonds C, Farquharson AL, Longo M, Minniti R, et al. OPRM1 A118G genotype fails to predict the effectiveness of naltrexone treatment for alcohol dependence. Pharmacogenet Genomics 2011;21(12):902-5. [PubMed: 21946895] 
34. Kranzler H, Armeli S, Covault J, Tennen H. Variation in OPRM1 moderates the effect of desire to drink on subsequent drinking and its attenuation by naltrexone treatment. Addict Biol In press.

35. Arias AJ, Armeli S, Gelernter J, Covault J, Kallio A, Karhuvaara S, et al. Effects of opioid receptor gene variation on targeted nalmefene treatment in heavy drinkers. Alcohol Clin Exp Res 2008;32(7):1159-66. [PubMed: 18537939]

36. Nealey KA, Smith AW, Davis SM, Smith DG, Walker BM. $\kappa$ - opioid receptors are implicated in the increased potency of intra-accumbens nalmefene in ethanol-dependent rats. Neuropharmacology 2011;61(1-2):35-42. [PubMed: 21338616]

37. Karhuvaara S, Simojoki K, Virta A, Rosberg M, Loyttyniemi E, Nurminen T, et al. Targeted nalmefene with simple medical management in the treatment of heavy drinkers: a randomized double- blind placebo-controlled multicenter study. Alcohol Clin Exp Res 2007;31(7):1179-87. [PubMed: 17451401]

38. Mitchell JM, Fields HL, White RL, Meadoff TM, Joslyn G, Rowbotham MC, et al. The Asp40 muopioid receptor allele does not predict naltrexone treatment efficacy in heavy drinkers. J Clin Psychopharmacol 2007;27(1):112-5. [PubMed: 17224736]

39. Tidey JW, Monti PM, Rohsenow DJ, Gwaltney CJ, Miranda R, Jr, McGeary JE, et al. Moderators of naltrexone's effects on drinking, urge, and alcohol effects in non-treatment-seeking heavy drinkers in the natural environment. Alcohol Clin Exp Res 2008;32(1):58-66. [PubMed: 18028530]

40. Chamorro A, Marcos M, Mirón-Canelo J, Pastor I, Gonzalez-Sarmiento R, Laso FJ. Association of $\mu$-opioid receptor (OPRM1) gene polymorphism with response to naltrexone in alcohol dependence: a systematic review and meta-analysis. Addict Biol 2012;17(3):505-12. [PubMed: 22515274]

41. LeMarquand D, Pihl RO, Benkelfat C. Serotonin and alcohol intake, abuse, and dependence: clinical evidence. Biol Psychiatry 1994;36(5):326-37. [PubMed: 7993959]

42. Kenna GA. Medications acting on the serotonergic system for the treatment of alcohol dependent patients. Curr Pharm Des 2010;16 (19):2126-35. [PubMed: 20482508]

43. Kranzler HR, Burleson JA, Brown J, Babor TF. Fluoxetine treatment seems to reduce the beneficial effects of cognitive-behavioral therapy in type B alcoholics. Alcohol Clin Exp Res 1996;20 (9): 1534-41. [PubMed: 8986200]

44. Pettinati HM, Volpicelli JR, Kranzler HR, Luck G, Rukstalis MR, Cnaan A. Sertraline treatment for alcohol dependence: interactive effects of medication and alcoholic subtype. Alcohol Clin Exp Res 2000;24(7):1041-9. [PubMed: 10924008]

45. Chick J, Aschauer H, Hornik K. Efficacy of fluvoxamine in pre- venting relapse in alcohol dependence: a one-year, double-blind, placebo-controlled multicentre study with analysis by typology. Drug Alcohol Depend 2004;74(1):61-70. [PubMed: 15072808]

46. Johnson BA, Roache JD, Javors MA, DiClemente CC, Cloninger CR, Prihoda TJ, et al. Ondansetron for reduction of drinking among biologically predisposed alcoholic patients: A randomized controlled trial. JAMA 2000;284(8):963-71. [PubMed: 10944641]

47. Lesch KP, Bengel D, Heils A, Sabol SZ, Greenberg BD, Petri S, et al. Association of anxietyrelated traits with a polymorphism in the serotonin transporter gene regulatory region. Science 1996;274 (5292):1527-31. [PubMed: 8929413]

48. Heils A, Teufel A, Petri S, Stober G, Riederer P, Bengel D, et al. Allelic variation of human serotonin transporter gene expression. J Neurochem 1996;66(6):2621-4. [PubMed: 8632190]

49. Hu XZ, Lipsky RH, Zhu G, Akhtar LA, Taubman J, Greenberg B, et al. Serotonin transporter promoter gain-of-function genotypes are linked to obsessive-compulsive disorder. Am J Hum Genet 2006;78(5):815-26. [PubMed: 16642437]

50. Praschak-Rieder N, Kennedy J, Wilson AA, Hussey D, Boovariwala A, Willeit M, et al. Novel 5HTTLPR allele associates with higher serotonin transporter binding in putamen: a [(11)C] DASB positron emission tomography study. Biol Psychiatry 2007;62(4):327-31. [PubMed: 17210141]

51 • ohnson BA, Ait-Daoud N, Seneviratne C, Roach JD, Javors MA, Wang XQ, et al. Pharmacogenetic approach at the serotonin transporter gene as a method of reducing the severity of alcohol drinking. Am J Psychiatry 2011;168(3):265-75. [PubMed: 21247998] The first, large, 
randomized, controlled trial in alcohol dependence, in which the patients were prospectively assigned to treatment based on genotype.

52. Kranzler HR, Armeli S, Tennen H, Covault J, Feinn R, Arias AJ, et al. A double-blind, randomized trial of sertraline for alcohol de- pendence: moderation by age of onset and 5-hydroxytryptamine transporter-linked promoter region genotype. J Clin Psychophar-macol 2011;31(1):22-30.

53. Bischof G, Grothues JM, Reinhardt S, Meyer C, John U, Rumpf HJ. Evaluation of a telephonebased stepped care intervention for alcohol-related disorders: a randomized controlled trial. Drug Alcohol Depend 2008;93(3):244-51. [PubMed: 18054443]

54. McKay JR, Alterman AI, Cacciola JS, O’Brien CP, Koppenhaver JM, Shepard DS. Continuing care for cocaine dependence: comprehensive 2-year outcomes. J Consult Clin Psychol 1999;67(3):420_ 7. [PubMed: 10369063]

55. McKay JR, Lynch KG, Shepard DS, Pettinati HM. The effectiveness of telephone-based continuing care for alcohol and cocaine dependence: 24-month outcomes. Arch Gen Psychiatry 2005;62(2): 199-207. [PubMed: 15699297]

56. McKay JR, Lynch KG, Shepard DS, Morgenstern J, Forman RF, Pettinati HM. Do patient characteristics and initial progress in treatment moderate the effectiveness of telephone-based continuing care for substance use disorders? Addiction 2005;100(2):216-26. [PubMed: 15679751]

57. McKay JR, Van Horn D, Oslin DW, Ivey M, Drapkin ML, Coviello DM, et al. Extended telephonebased continuing care for alcohol dependence: 24-month outcomes and subgroup analyses. Addiction 2011;106(10):1760-9. [PubMed: 21545667]

58. O’Malley SS, Rounsaville BJ, Farren C, Namkoong K, Wu R, Robinson J, et al. Initial and maintenance naltrexone treatment for alcohol dependence using primary care vs specialty care: a nested sequence of 3 randomized trials. Arch Intern Med 2003;163 (14):1695-704. [PubMed: 12885685]

59. Friedmann PD, Hendrickson JC, Gerstein DR, Zhang Z. The effect of matching comprehensive services to patients' needs on drug use improvement in addiction treatment. Addiction 2004;99(8): 962-72. [PubMed: 15265093]

60. Brooner R, Kidorf M. Using behavioral reinforcement to improve methadone treatment participation. Sci Pract Perspect 2002;1:38-46. [PubMed: 18567965]

61. King VL, Stoller KB, Hayes M, Umbricht A, Currens M, Kidorf MS, et al. A multicenter randomized evaluation of methadone medical maintenance. Drug Alcohol Depend 2002;65(2): 137-48. [PubMed: 11772475]

62. Kidorf M, Neufeld K, Brooner RK. Combining stepped- care approaches with behavioral reinforcement to motivate employment in opioid-dependent outpatients. Subst Use Misuse 2004;39(13-14):2215-38. [PubMed: 15603002]

63. Brooner RK, Kidorf MS, King VL, Stoller KB, Neufeld KJ, Kolodner K, et al. Comparing adaptive stepped care and monetary-based voucher interventions for opioid dependence. Drug Alcohol Depend 2007;88 Suppl 2:S14-23.

64. Kakko J, Gronbladh L, Svanborg KD, von Wachenfeldt J, Ruck C, Rawlings B, et al. A stepped care strategy using buprenorphine and methadone versus conventional methadone maintenance in heroin dependence: a randomized controlled trial. Am J Psychiatry 2007;164(5):797-803. [PubMed: 17475739]

65. Marlowe DB, Festinger DS, Arabia PL, Dugosh KL, Benasutti KM, Croft JR, et al. Adaptive Interventions in Drug Court: A Pilot Experiment. Crim Justice Rev 2008;33(3):343-60. [PubMed: 19724664] 